\title{
Coffee cup model of the cavernous sinus
}

\author{
Leonard Kranzler \\ Department of Neurological Surgery, University of Chicago, Chicago, IL, USA
}

\begin{abstract}
The cavernous sinuses are complicated venous structures comprising important neurovascular structures, the internal carotid artery and the oculomotor, trochlear, ophthalmic, maxillary and abducens nerves. Injury to these structures can lead to severe neurovascular complications and even to death. The sinus may be invaded by neoplastic, infectious, inflammatory, and vascular processes. A precise knowledge of the complex anatomy of the cavernous sinus and anatomical orientation is essential for surgery in this area. This work presents a coffee cup model of the cavernous sinus to aid in learning the cavernous sinus anatomy.
\end{abstract}

Keywords: anatomy; cavernous sinus; teaching model

Anatomy 2015;9(1):34-37 @2015 Turkish Society of Anatomy and Clinical Anatomy (TSACA)

\section{Introduction}

The cavernous sinus (CS) is a complex venous space that lies on the lateral sides of the sella turcica surrounded by the meningeal and periosteal dural folds. The sinus extends from the superior orbital fissure to the apex of the petrous temporal bone, with an average length of 2 $\mathrm{cm}$ and a width of $1 \mathrm{~cm}$. The internal carotid artery (ICA), with the sympathetic plexus around it, passes forward through the sinus together with the abducens nerve (VI) which lies lateral to the artery. The oculomotor (III) and trochlear nerves (IV) and the ophthalmic (V1) and maxillary divisions (V2) of the trigeminal nerve all lie in the lateral wall of the sinus. ${ }^{[1]}$

The lateral wall of the CS has two layers; the external layer is thick and pearly grey, and the internal is semitransparent and contains the cranial nerves. These layers can be surgically separated to expose the III, IV and V1. The medial wall of the CS has two areas, sellar and sphenoidal, both of which are made up of one dural layer only. The superior wall, also called the CS roof, is formed by three triangles: oculomotor, clinoid and carotid triangles. CN III is located in a cisternal space in the oculomotor triangle. The posterior wall is part of the dura that covers the clivus, made up of the meningeal and periosteal dural layers. This wall is close to the vertical segment of the abducens nerve (VI), from the point of its dural perforation to where it changes direction at the level of Dorello's canal. The cavernous segment of the ICA with its accompanying sympathetic neural plexus continues just medial to the CN VI. The ICA and $\mathrm{CN}$ VI pass through the CS sinusoids. ${ }^{[2]}$ Cranial nerves III, IV, and V1 exit the cranium through the superior orbital fissure, the V2 exits the cranium through the foramen rotundum.

The anatomical structures of the CS can be invaded by neoplastic, infectious, inflammatory, and vascular lesions. There are two ways of approaching the CS, intradural, with access to the CS via its dural roof through the anteromedial or medial triangle; and extradural, with access to the CS through its lateral wall, through the paramedial, Parkinson's, anterolateral or lateral triangles after surgically separating the two dural layers and identifying $\mathrm{CN}$ III, IV, and V. A posterior approach is also possible, though very difficult. ${ }^{[3,4]}$ The choice of surgical approach depends mainly on the location of the lesion and its nature.

A precise knowledge of the complex anatomy of the CS, together with pathological processes and their imaging characteristics will enable accurate evaluations of the conditions that affect the CS. This article presents a model (coffee cup model) of the CS that enables us to learn morphological features of the CS. 
A coffee cup model of the cavernous sinus enables us to see in three dimensional perspective and to learn,

- The relationship of the oculomotor (III) and trochlear (IV) nerves to the tentorium,

- The relationship of the optic (II) nerve to the internal carotid artery,

- The relationship of the abducens (VI) nerve to the carotid artery,

- The nerve that goes through the inferior orbital fissure (IOF),

- The nerves that go through the superior orbital fissure (SOF),

- The relationships of the nerves that go through the SOF,

- The nerve that enters the pterygopalatine fossa (PP),

- The nerve that goes under the petrosphenoid ligament,

- The site of origin of the meningohypophseal artery branches and,

- The relationships that form the cavernous sinus triangles.

\section{Materials and Methods}

Coffee cup model of the CS is prepared with a paper coffee cup and 8 colored pipe cleaners (Figure 1). Outline bottom and orbital entrance. Start with drawing circles on bottom of the cup and punching the circles out with a paper clip. Outline your cup - draw a tentorial line on side of cup. Add circles for III, IV, V, and VI (Figures 2-4). Label Gasserian V and Dorello VI petrosphenoid (Figure 3). Add circles for SOF, IOF and optic foramen on the bottom of the cup (back wall of the orbit) (Figure 4). A total of thirteen openings are added to the coffee cup for this model.

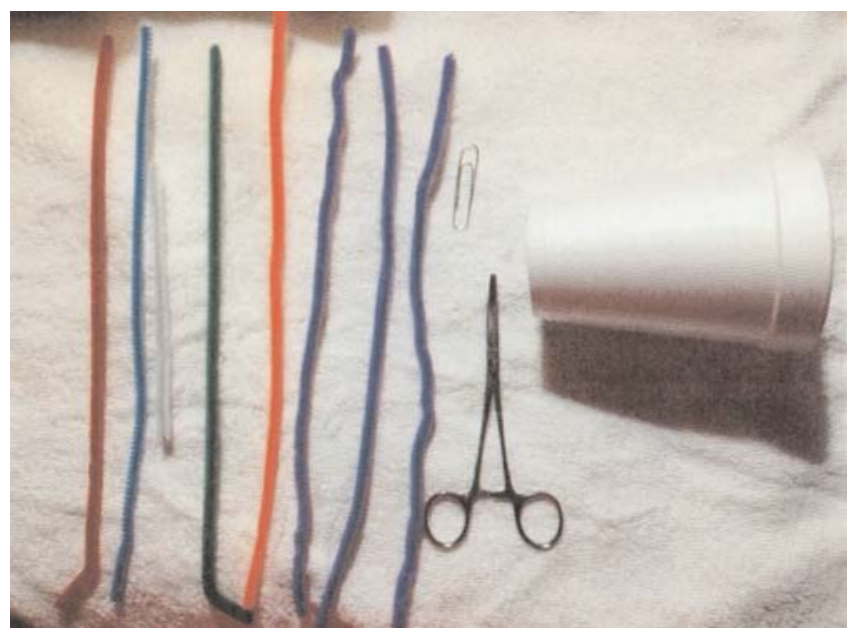

Figure 1. Take a paper coffee cup and 8 colored pipe cleaners.

\section{Steps to follow}

- 1st - internal carotid artery (Figure 5) - add carotid with proximal and distal angle

- 2nd - add abducens (VI) nerve next to carotid (on lateral aspect) out through SOF (Figure 6)

- 3 rd - add optic nerve (II) (Figure 7)

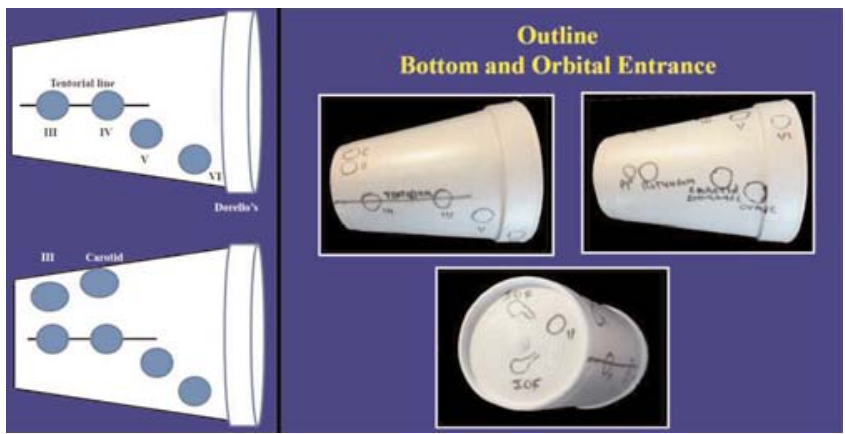

Figure 2. Tentorial line and structures on side of the cup. Add circles for III, IV, V, and VI.

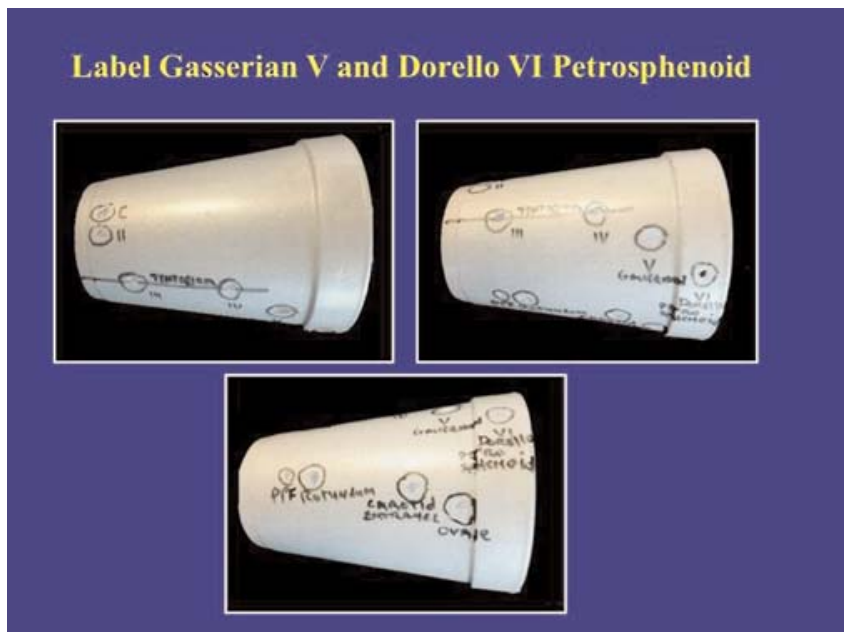

Figure 3. Label Gasserian V and Dorello VI petrosphenoid.
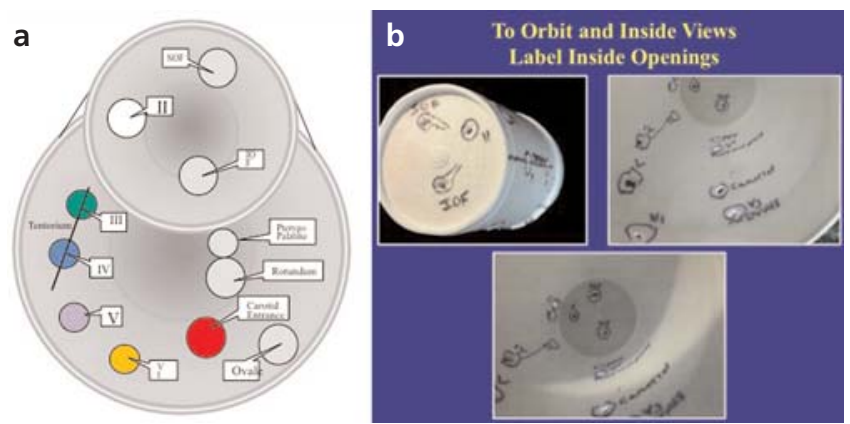

Figure 4. (a, b) Draw circles on the bottom and outer surface of the coffee cup for cavernous sinus structures. Label inside openings. 
- 4th - add oculomotor nerve (III) out through SOF (Figure 8)

- 5 th - add trochlear (IV) out through SOF (Figure 8)

- 6th - add trigeminal (V)

- 7th - add ophthalmic nerve V1 - out through SOF (Figure 9)

- 8th - add maxillary nerve V2 - out foramen rotundum into pterygopalatine fossa and then into the IOF (Figure 10)

- 9th - add mandibular nerve V3 - out foramen ovale (Figure 11)

\section{Cavernous sinus model triangles}

There are eight triangles in the cavernous sinus coffee cup model (Figure 12).

- Clinoidal triangle (CT) between the optic (II) and oculomotor (III) nerves

- Oculomotor triangle (OT) between the oculomotor (III) nerve and the dura it enters

- Supratrochear triangle (ST) between the oculomotor (III) and trochlear (IV) nerves

- Infratrochear triangle (IT) between the trochlear nerve (IV) nerve and V1 (ophthalmic) nerve also called Parkinson's triangle

- Anteromedial triangle (AM) between V1 (ophthalmic) and V2 (maxillary) nerves

- Anterolateral triangle (AL) between V2 (maxillary)and V3 (mandibular) nerves

- Posterolateral triangle (PL) Mandibular nerve lateral to the greater superficial petrosal nerve (Glasscock's)

- Posteromedial triangle (PM) Mandibular nerve medial to the greater superficial petrosal nerve (Kawase's)

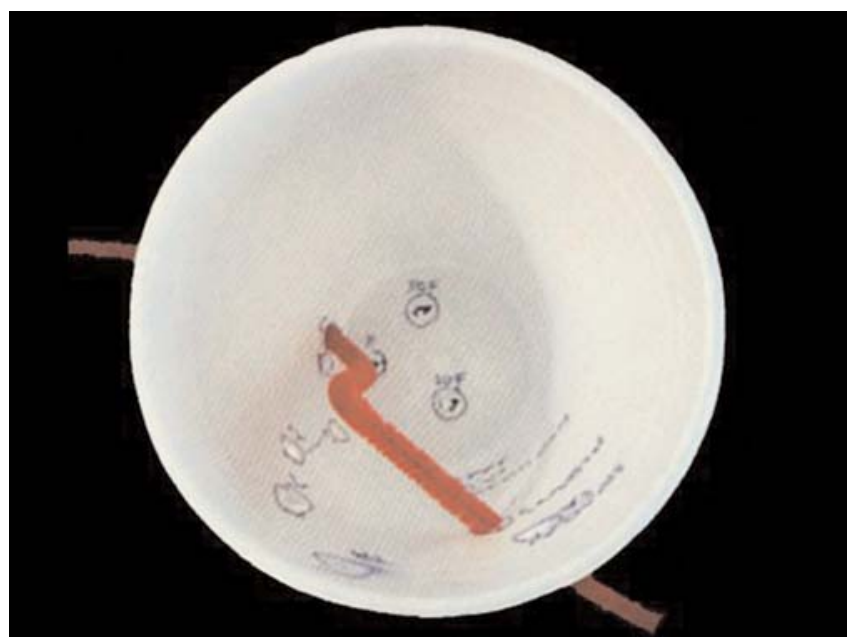

Figure 5. Internal carotid artery in the CS. Add carotid with proximal and distal angle.

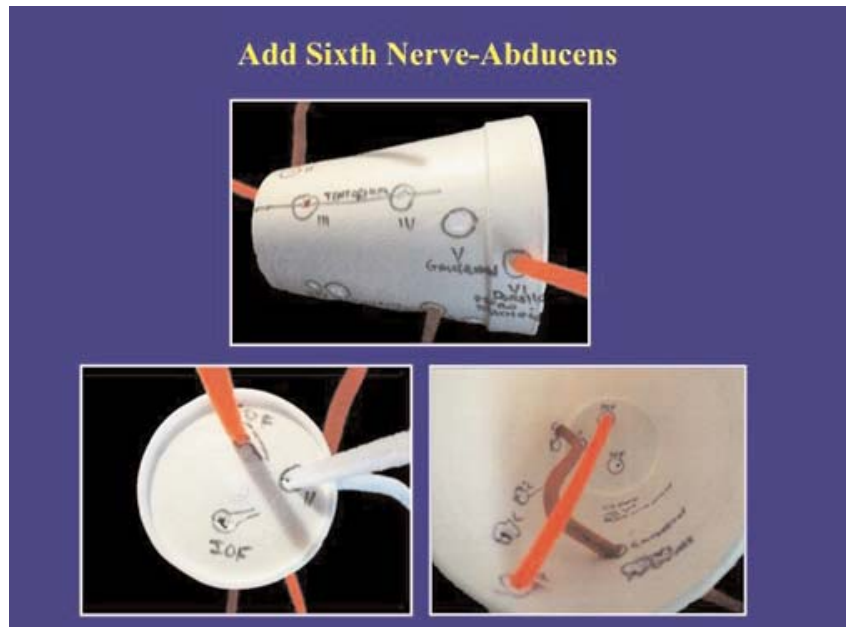

Figure 6. Add sixth nerve - abducens.

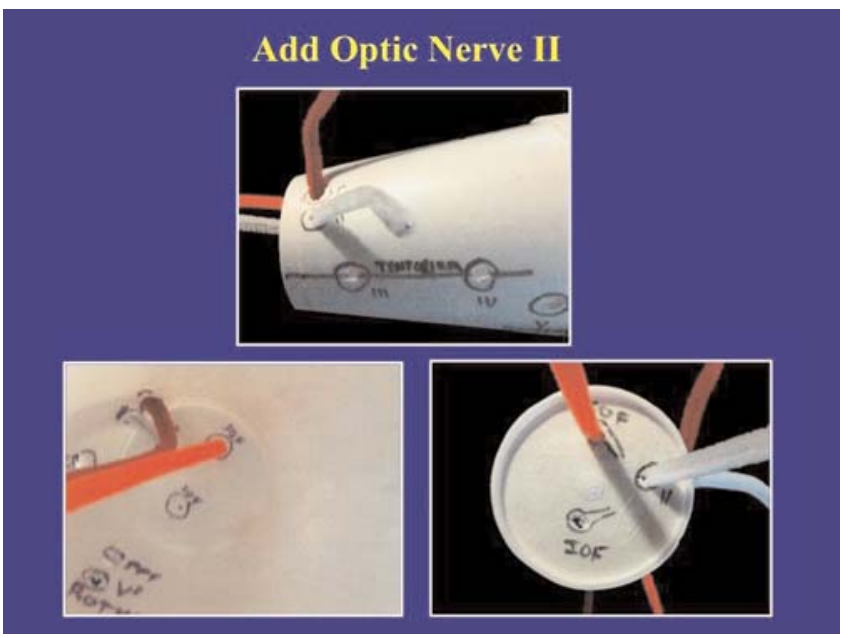

Figure 7. Add optic nerve (II).

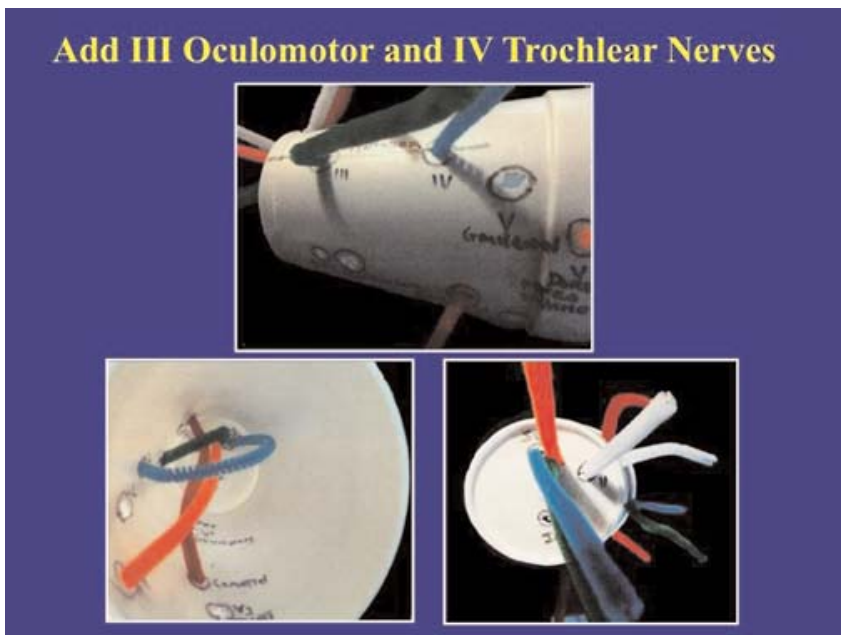

Figure 8. Add oculomotor nerve (III) out through SOF and trochlear nerve (IV) out through SOF. 


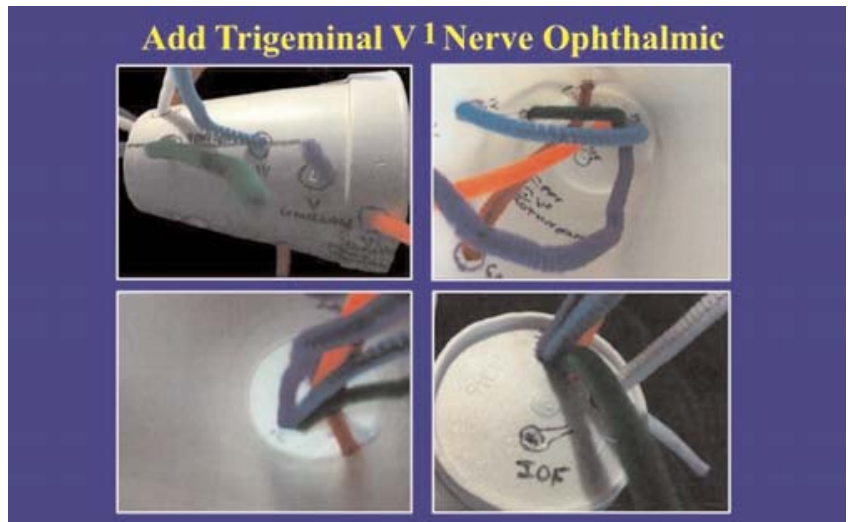

Figure 9. Add ophthalmic nerve V1 - out through SOF.

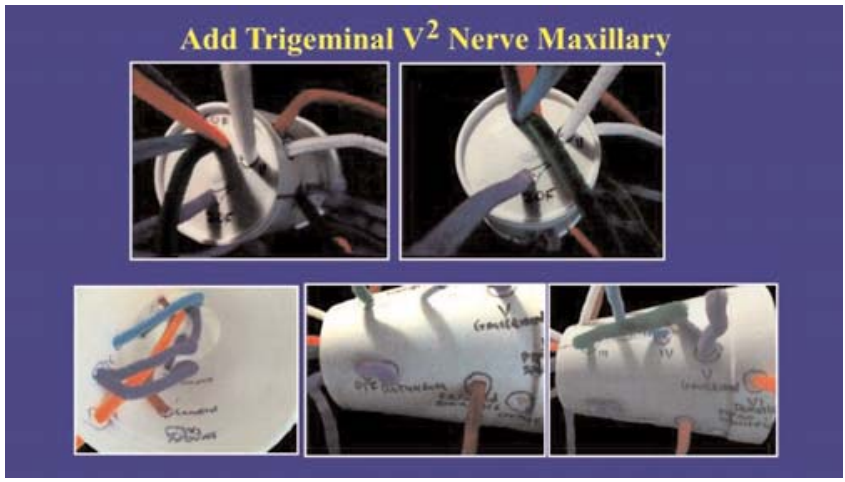

Figure 10. Add maxillary nerve V2 - out foramen rotundum into pterygopalatine fossa and then into the IOF.

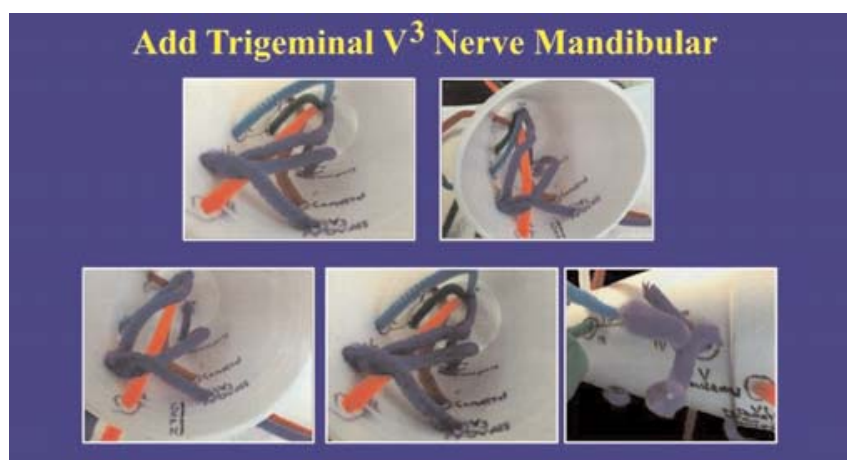

Figure 11. Add mandibular nerve V3 - out foramen ovale.

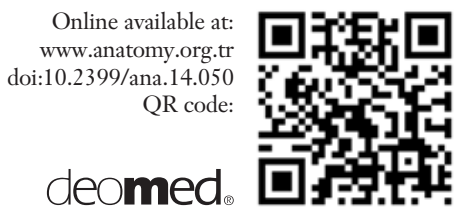

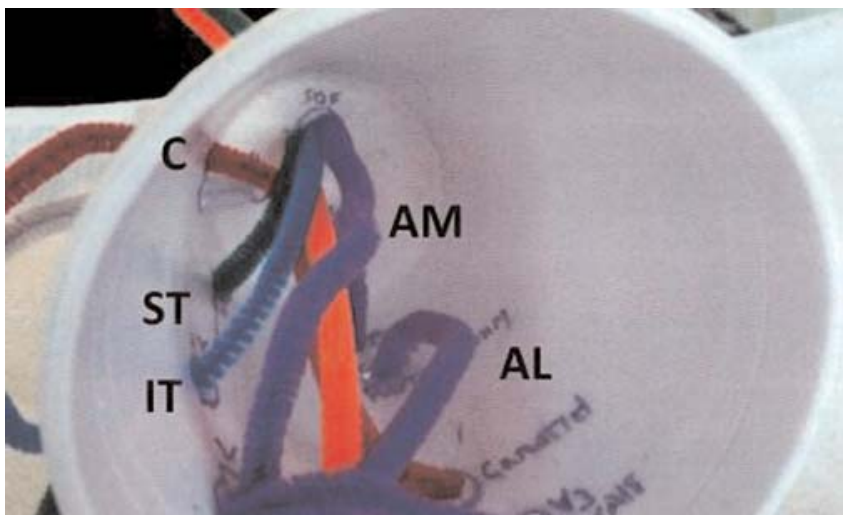

Figure 12. Triangles of the CS. AL: anterolateral triangle; AM: anteromedial triangle; CT: clinoidal triangle; IT: infratrochear triangle; OT: осUlomotor triangle; PL: posterolateral triangle; PM: Posteromedial triangle; ST: supratrochear triangle.

\section{Conclusion}

The complex structure and important vascular and neural contents of the CS,makes it very difficult for the neurosurgeon to reach and operate on the sinus. Understanding of the microsurgical anatomy of the region is essential for operating in and around the CS. This manuscript is a model of the CS for understanding its complex anatomy. Once the student has experience with the model above (the right cavernous sinus) he should practice creating the left cavernous sinus.

\section{References}

1. Mancall EL, Brock DG, editors. Gray's Clinical neuroanatomy: the anatomic basis for clinical neuroscience. Philadelphia: Elsevier Saunders; 2011. p. 75.

2. Campero A, Campero AA, Martins C, Yasuda A, Rhoton AL Jr. Surgical anatomy of the dural walls of the cavernous sinus. J Clin Neurosci 2010;17:746-50.

3. Yasuda A, Campero A, Martins C, Rhoton AL Jr, de Oliveira E, Ribas GC. Microsurgical anatomy and approaches to the cavernous sinus. Neurosurgery 2005;56 (1 Suppl):4-27.

4. Kayalioglu G, Govsa F, Erturk M, Pinar Y, Ozer MA, Ozgur T. The cavernous sinus: topographic morphometry of its contents. Surg Radiol Anat 1999;21:255-60.

Correspondence to: Leonard Kranzler, MD Northside Neurosurgical $3000 \mathrm{~N}$ Halsted St Suite \#605, Chicago, IL 60657, USA Phone: +1 773 348-4333 e-mail: kranzlermd@gmail.com Conflict of interest statement: No conflicts declared.

This is an open access article distributed under the terms of the Creative Commons Attribution-NonCommercial-NoDerivs 3.0 Unported (CC BY-NCND3.0) Licence (http://creativecommons.org/licenses/by-nc-nd/3.0/) which permits unrestricted noncommercial use, distribution, and reproduction in any medium, provided the original work is properly cited. Please cite this article as: Kranzler L. Coffee cup model of the cavernous sinus. Anatomy 2015;9(1):34-37. 